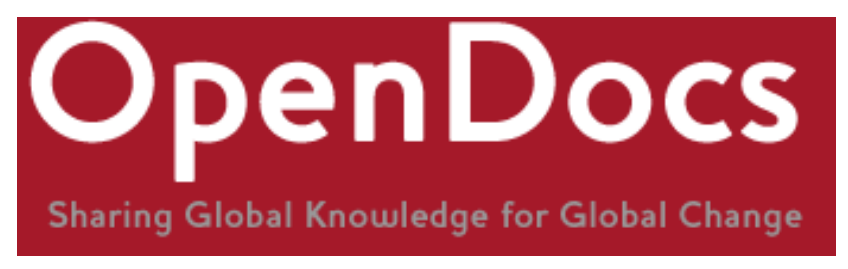

Title: Who shares risk with whom under different enforcement mechanisms?

Citation: Abigail Barr / Marleen Dekker / Marcel Fafchamps, "Who Shares Risk with Whom under Different Enforcement Mechanisms?" Economic Development and Cultural Change 60, no. 4 (July 2012): 677-706. DOI: 10.1086/665599

Official URL: http://dx.doi.org/10.1086/665599

More details/abstract: This review of literature looks at the micro-political mechanisms through which unorganised labour makes gains in wages and conditions of work, in a context of real wage rises since about 2005 and the ubiquity of informal labour contracts. It examines the micro level impact of demand and supply factors, the pressures on employers to concede to demands and the various methods used by labour to push its positions.

Version: Accepted version.

Terms of use: This document is the author's final accepted version of the journal article. There may be differences between this version and the published version. You are advised to consult the publisher's version if you wish to cite from it: http://dx.doi.org/10.1086/665599

This is a download from OpenDocs at the Institute of Development Studies

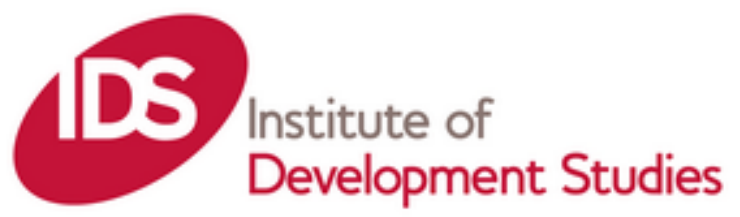




\title{
Who Shares Risk with Whom under Different Enforcement
}

\section{Mechanisms?*}

\author{
Abigail Barr \\ Marleen Dekker \\ Marcel Fafchamps \\ Oxford University ${ }^{\dagger}$ \\ African Studies Centre Leiden \\ Oxford University ${ }^{\ddagger}$
}

January 2011

\begin{abstract}
We investigate whether available enforcement mechanisms affects who shares risk with whom in sub-Saharan Africa by applying dyadic regression analysis to data from a lab-type experiment, surveys and a genealogical mapping exercise. During the experiment participants were invited to form risk sharing groups under three enforcement mechanisms: external, intrinsic, and extrinsic, i.e., social sanctioning. Same sex dyads and dyads who belong to the same economic community-based organizations (CBOs) are more likely to share risk. However, when social sanctioning is possible, co-members in economic CBOs withdraw from group formation and co-religion and marriage ties come to the fore.
\end{abstract}

\footnotetext{
${ }^{*}$ We thank Trudy Owens for making available some of the survey data used in our analysis. We benefited from useful comments from Stefan Dercon, Tessa Bold, Garance Genicot, and Orazio Atanasio, as well as from participants in the 2008 CSAE Conference and from seminar participants at Boston University and the Universities of Nottingham and Auvergne. The support of the Economic and Social Research Council (UK), the Department for international Development and the Netherlands Organisation for Scientific Research (NWO/WOTRO) is gratefully acknowledged. The usual disclaimer applies.

${ }^{\dagger}$ Oxford Department of International Development, University of Oxford

${ }^{\ddagger}$ Department of Economics, University of Oxford, Manor Road, Oxford OX1 3UQ. Email: marcel.fafchamps@economics.ox.ac.uk. Fax: +44(0)1865-281447. Tel: +44(0)1865-281446.
} 


\section{Introduction}

It is common for households to pool or share risk, for instance through mutual insurance arrangements (e.g. Foster and Rosenzweig 2001, Fafchamps and Lund 2003, De Weerdt and Fafchamps 2007) and group loans with joint liability (e.g. Besley and Coate 1995, Ghatak 2000, Ghatak 1999, Morduch 1999). The way in which risk sharing arrangements are enforced varies with the institutional and legal environment. Informal arrangements are thought to be enforced through a mix of quid pro quo, altruism, and adherence to social norms (e.g. Coate and Ravallion 1993, Cox and Fafchamps 2007, Platteau 1994). Formal arrangements, such as insurance contracts and funeral societies, combine the above with external enforcement through courts and other adjudication processes (e.g. De Weerdt and Dercon 2006, De Weerdt, Dercon, Bold and Pankhurst 2006). What remains unclear is whether and how the nature of the available enforcement mechanisms affects who shares risk with whom. We investigate this issue using a laboratory-type experiment designed specifically for this purpose and conducted in the field.

Following the seminal work of Kimball (1988) and Coate and Ravallion (1993), the theoretical literature has modelled informal risk sharing as a repeated game, in some cases, between self-interested parties (e.g. Kocherlakota 1996, Ligon, Thomas and Worrall 2001, Foster and Rosenzweig 2001) and, in others, between parties who are intrinsically motivated by feelings of altruism and anticipated guilt (e.g. Altonji, Hayashi and Kotlikoff 1992, Ravallion and Dearden 1988, Cox 1987, Cox, Eser and Jimenez 1998, Cox and Fafchamps 2007). This theoretical literature predicts that external enforcement overcomes the limitations imposed by dependency on intrinsic incentives and social enforcement. Consequently, it facilitates risk sharing between individuals who have little knowledge of one another and who neither trust nor care about one another's wellbeing. ${ }^{1}$

\footnotetext{
${ }^{1}$ Genicot and Ray (2003) and Bloch, Genicot and Ray (2004) discuss the limitations imposed by self-
} 
The primary purpose of this paper is to seek empirical support for predictions derived from this literature using data from a controlled behavioral experiment conducted in rural Zimbabwe. The advantage of using an experimental approach is that it facilitates causal inference. This is because the possible effect of who groups with whom on the enforcement mechanism that emerges is ruled out by design, leaving only the effect of the latter on the former to be identified. However, the approach requires that the participating subjects be placed in a somewhat artificial decision-making environment. This may cast doubt on whether the behavior observed during the experiment bears any resemblance to the corresponding behavior as it naturally arises (e.g. Bardsley 2005, Levitt and List 2007). We aim to minimize this potential drawback in three ways. First, the experimental subjects are villagers who are known to engage in informal risk sharing. Second, each experimental session is conducted in a single village to ensure that the participants interact with people they already know. Third, the experiment is designed to allow face-to-face, rather than anonymous, interaction. A comparison of behavior within the experiment with real risk sharing within a sub-sample of villages indicates that these measures are at least partially successful (Barr and Genicot 2008).

The experiment involves two rounds, played over two consecutive days. In the first round, participants independently play a version of Binswanger's gamble choice game (Binswanger 1980). In the second round, participants play the game a second time but are offered, ex ante, the opportunity to form risk sharing groups. Within each group the proceeds of all members' gambles are shared equally. The institutional environment and, hence, the set of available enforcement mechanisms, is varied across three treatments applied during the second round.

In the first treatment, agreements to share winnings are externally enforced by the experimenter. In the second treatment, participants can secretly defect from an agreement after enforcement on the formation of risk sharing networks. 
observing the outcome of their own gamble. This implies that agreements are enforced only by intrinsic motivations (e.g., altruism and guilt). In the third treatment, participants can defect from an agreement after observing the outcome of their own gamble, but they have to publicly confirm their defection to everyone in the session. This implies that extrinsic incentives in the form of social sanctions (e.g., shaming, threatened exclusion) can be brought to bear as additional incentives to deter defection.

Using the data generated by the experiment, Barr and Genicot (2008) show that individuals are most likely to enter into risk sharing agreements when those agreements are externally enforced, although even then many potentially beneficial agreements are not entered into. ${ }^{2}$ They also show that it is only under external enforcement that group formers engage in more risk taking. Further, in disagreement with the theoretical literature cited above, they find that individuals are least likely to enter into risk sharing arrangements in the third treatment. They go on to show that this third finding is consistent with two possible theoretical explanations: either social sanctions, in the form of full or partial exclusion, are costly to inflict; or individuals suffer from time-inconsistent preferences. However, they do not test either of these theories.

In contrast to Barr and Genicot (2008), the focus of this paper is on who commits to share risk with whom under each of the three treatments. We investigate this by combining the experimental data with information from two surveys and a genealogical mapping exercise that focus on the same sample of households. These additional sources of information provide a rich description of the economic and social contexts of the experimental participants, including data on the kinship and marriage ties they share, and the various churches and community based organizations (CBOs) to which they belong. To our knowledge, this is the first time that

\footnotetext{
${ }^{2}$ Barr and Genicot's probit model for the individual decision to join a group in the experiment shows that the institutional (treatment) and regional environment (research area) are important predictors of group formation. The sex and education level of the participant also have marginal effects, while other individual characteristics such as age, being a household head and being married do not affect group formation.
} 
experimental data on group formation has been so richly complemented by pre-collected survey and genealogical information.

Our findings can be summarized as follows. In general, a pair of individuals is more likely to share risk the more similar they are in terms of age and gender. Belonging to the same religious group and being related by marriage support enforcement through social sanctioning, possibly because each is associated with behavioral rules that are traditionally enforced through status manipulation, shame and guilt. In contrast, while co-members in economic CBOs are highly likely to group together when risk sharing relations are enforced either externally or by intrinsic incentives, they tend not to group together when social sanctions can be brought into play. This is consistent with social sanctions being costly to both sanctioners and sanctionees when applied within the context of these relationships because it would undermine the functioning of the organizations to which both belong.

The paper is organized as follows. We begin in Section 2 by presenting the experimental design. In section 3, we draw on existing theory to develop a set of predictions about who groups with whom in various contract enforcement environments. In section 4 , we describe our testing strategy. Data sources and variable construction are discussed in Section 5. In Section 6, we present summary statistics relating to the experiment and, in Section 7 we present the empirical results. Section 8 concludes.

\section{Experimental design}

The experiment is based on a simple gamble choice game played with villagers in 14 different villages. In every village, each household is invited to send one adult, preferably the household head or his/her spouse, to participate in the games played in their village. Each participant plays the game twice, once on the first day and a second time the next day. Each round takes 
between one and two hours.

In each round, each participant is interviewed privately and asked to select one of six possible gambles $g$, ranked from the least (1) to the most risky (6). The gamble choice set is the same for all participants. Riskier gambles have higher expected returns. A similar game structure was originally used by Binswanger (1980) to elicit risk preferences; the choice of gamble implies a range of possible values for the individual's coefficient of relative risk aversion. The gambles used in our experiment are presented in Table 1 together with the implied ranges of the risk aversion coefficient. ${ }^{3}$

On the first day, each participant plays the game individually and winnings are distributed at the end of play. At the end of the first day's round, participants are told to come back the next day to play the game a second time. They are informed that the next day, before choosing their gambles, they can if they wish form groups with other participants and that those in a group will share second day winnings equally. ${ }^{4}$ There are no restrictions on the size or composition of groups. Before going home, participants attend a training session during which they are shown how forming a group to pool winnings reduces risk, and how and to what extent the grouping arrangements will be enforced.

On the second day, participants are first asked to declare whether they have formed a group and with whom. Participants in a group have to register together and their intention to form a group is recorded by the enumerators. After all groups have been declared and agreed on,

\footnotetext{
${ }^{3}$ The gambles are expressed in Zimbabwean $\$$. The official exchange rate at the time of the experiment was around Z $\$ 55$ for US $\$ 1$ while the black market rate was around 2.5 times that amount. In the areas where the experiment was conducted and at the time of the experiments, the daily wage for a farm labourer was around $\mathrm{Z} \$ 200$, similar in magnitude to the average winnings per round from the experiment of $\mathrm{Z} \$ 158$ in round 1 and $\mathrm{Z} \$ 172$ in round 2.

${ }^{4}$ The decision to impose equal sharing was not taken lightly as informal risk sharing arrangements in everyday life are unlikely to have this quality. However, after only one pilot session in the field, it became clear that the only way to ensure that the participants focused on who to share with given the enforcement mechanism was to simplify as much as possible the issue of how to share. The equal sharing rule proved to be the easiest to explain in terms of the consequences of both joining a group and reneging and was, thus, implemented throughout the data generating phase of the project.
} 
each participant proceeds to select one of the six gambles again individually and privately. At the end of play, winnings are calculated, pooled and shared equally for those in groups, and privately distributed to all participants.

The verbal framing of the game is kept to a minimum and, as a consequence, the game can be likened to a variety of real life situations, including risk sharing, which has been extensively studied in village communities (e.g. Udry 1994, Ligon et al. 2001, Fafchamps and Lund 2003), and group lending with joint liability (e.g. Karlan 2007, Besley and Coate 1995, Ghatak 1999, Ghatak 2000)..$^{5}$

To facilitate an analysis of the effect of different enforcement mechanisms on who groups, with whom to share risk, three treatments are applied during the experiment. Under treatment 1, sharing is enforced by the experimenter: once participants have declared a group, they cannot subsequently change their mind, i.e., they cannot refuse to share their second day winnings with others in their group. So, regardless of the outcomes of all their gambles, their winnings are pooled and shared equally. Under treatment 2, after having selected a gamble and observed their individual winnings (but not those of others in their group), participants are offered a chance to defect from their group, i.e., they can decide to keep their individual winnings. If they opt to do so, they do not receive a share of the winnings of others in their group. Treatment 3 is similar to treatment 2 except that participants who elect to keep their individual winnings instead of sharing have to confirm their decision publicly in front of everyone participating in the same experimental session. Under each treatment, the consequences of and rules relating to group formation and defection are explained to participants during the training session on day one. ${ }^{6}$

The treatments facilitate an analysis of the effect of different forms of enforcement on who

\footnotetext{
${ }^{5}$ There is no lending in our experiment, but participants de facto invest a sure amount (gamble 1) into various risky investments (gambles 2 to 6 , see Table 1 ).

${ }^{6}$ No rules were applied to or recommendations made concerning gamble choices within groups.
} 
shares risk with whom in the following way. In treatment 1 , the risk sharing arrangements are perfectly and exogenously enforced by the experimenter. In treatment 3 , defection is public and can therefore trigger social punishment after the game is completed. Enforcement is extrinsic in the sense that it relates to the importance that individuals place on their repeated economic and social interactions within the village and whether and how they think these interactions might be damaged should they defect publicly during the experiment. In contrast, in treatment 2 defection is private and the identity of a defector is either impossible or difficult to detect. ${ }^{7}$ In this treatment, enforcement is thus primarily, if not exclusively, based on intrinsic incentives: altruism, reciprocity, and a desire to avoid feelings of guilt.

Each of the 14 villages studied here was randomly assigned to one of the three treatments. All the participants in a single village receive the same treatment. Because the total number of villages is small, possible imbalances may arise between villages. We describe how we deal with this in the testing strategy section below.

\section{Theory and predictions}

Our objective is to identify the effects of imperfect enforcement on who shares risk with whom. This is an empirical contribution, so we do not present a fully specified theoretical model of group formation for risk sharing. Instead, we combine insights drawn from the already rich and diverse theoretical and econometric literature on this topic with ethnographic information pertaining to the villages in our study to generate a series of testable predictions.

First, given the symmetry of the game and the nature of the gamble choice task, it is useful

\footnotetext{
${ }^{7}$ Given that participants had only a small number of gambles to choose from, under treatment 2, they may have been able to draw limited inferences about whether others defected from the amount of money that is distributed to them at the end of day two. However, as noted by Barr and Genicot (2008), inference is impossible in groups of size 2 because the other player can always claim to have selected the same gamble and gotten the same outcome. In groups of 3 or more, it is theoretically possible to infer that someone has defected, but impossible to tell who.
} 
to consider what groups would be formed among identically risk averse agents. Under perfect exogenous enforcement, i.e., enforcement by the experimenter, individuals should group as long as the mutual insurance benefit exceeds the costs of group formation. Let $\pi(s)$ denote the benefit derived from joining a group of size $s$ and let the cost of joining the group be $c$. Cost $c$ represents the time and effort required, during the 24 hour interval between the two rounds of the experiment, to agree with others to group and share winnings. For now we assume $c$ to be the same for all participants. In general, $\pi(s)$ increases with $s$ but at a decreasing rate. ${ }^{8}$ It follows that if $c>0$ there is an upper limit $s^{*}$ on group size determined by $\pi^{\prime}\left(s^{*}\right)=c$. If $c=0$, it is optimal for all participants to join a single, village-wide group.

Differences between participants in risk attitudes may affect group formation. Assortative matching by risk attitudes has been discussed in detail by Legros and Newman (2007) in the context of marriage markets with non-transferable utility. They show that, if the form of risk sharing is unrestricted, risk averse and risk neutral individuals will marry so that the latter can insure the former. However, this is precluded in our experiment because we impose equal sharing of winnings within groups. With equal sharing exogenously imposed, Legros and Newman's (2007) model predicts positive assortative grouping on risk attitudes. ${ }^{9}$ Atanasio et al. (2009) find support for this prediction among close friends and kin using experimental data from Colombia.

Legros and Newman (2007) do not, however, explore the impact of risk attitudes on the likelihood that an individual chooses to marry or remain single. In our experiment some par-

\footnotetext{
${ }^{8}$ This is most easily shown if we ignore gamble choices. Let $y_{i}$ be individual $i$ 's winnings and let average winnings in a group of size $s$ be $y_{s}=\frac{1}{s} \sum_{i=1}^{s} y_{i}$. Given the experimental setting, the $y_{i}$ 's are i.i.d. Mean winnings are unaffected by group size: $E\left[y_{s}\right]=E\left[y_{i}\right] \forall s$. The variance of $y_{s}$, however, falls with $s: \operatorname{Var}\left[y_{s}\right]=$ $\frac{1}{s^{2}} \sum_{i=1}^{s} \operatorname{Var}\left(y_{i}\right)=\frac{\sigma}{s}$ where $\sigma \equiv \operatorname{Var}\left(y_{i}\right)$. It follows that the utility $v(y)$ of any risk averse individuals increases in $s$ but at a decreasing rate, i.e., $v\left(y_{s}\right)-v\left(y_{s-1}\right)<v\left(y_{s+1}\right)-v\left(y_{s}\right)$ since$$
\operatorname{Var}\left[y_{s-1}\right]-\operatorname{Var}\left[y_{s}\right]=\frac{\sigma}{s-1}-\frac{\sigma}{s}>\operatorname{Var}\left[y_{s}\right]-\operatorname{Var}\left[y_{s+1}\right]=\frac{\sigma}{s}-\frac{\sigma}{s+1}
$$

${ }^{9}$ Athough the authors do not emphasize the fact in their paper, the model presented in Barr and Genicot (2008) similarly predicts assortative matching on risk attitudes.
} 
ticipants may choose not to group. If we assume that $c$ is constant across individuals, more risk averse individuals will be more likely to group as it is they who benefit most from mutual insurance. For risk neutral individuals, the gain from grouping is zero and thus does not exceed the cost of forming a group as long as $c>0$. Combined, these two observations imply that, if $c>0$, multiple risk sharing groups will be observed in each village, participants will sort into groups with reference to their risk attitudes, and less risk averse individuals may not group or, put another way, may stay in groups of one. So, our first prediction concerning who shares risk with whom is as follows:

Prediction 1: Participants who are more similar with respect to their revealed risk attitudes are more likely to group to share risk.

In practice, group formation costs $c$ are likely to vary across pairs of individuals (Fafchamps and Gubert 2007). Some pairs will be more socially proximate, i.e., they will be used to interacting with one another because they are related by blood or marriage, or belong to the same religious congregation or CBOs. These pairs will have lower group formation costs and, other things being equal, will be more likely to group (Arcand and Fafchamps, 2010). Pairs who are similar with respect to gender, age, education, role within the household, and possibly income and wealth may also face lower group formation costs as they will find it easier to communicate and negotiate with one another. So, our second and third predictions concerning who shares risk with whom are as follows:

Prediction 2: Participants who are more similar in terms of gender, age, education, and so on are more likely to group together to share risk during the experiment.

Prediction 3: Participants who are socially proximate because they are kin, or belong to the same religious congregation, or are co-members in CBOs are more likely to group together to share risk during the experiment. 
So far we have assumed that risk sharing is perfectly enforced. Now we turn to the likely effects of imperfect enforcement on who shares risk with whom and, hence, to the predictions that are of principal interest.

In the absence of any enforcement, the best response for a selfish individual is to cheat, i.e., join a group, take a high risk gamble, share winnings if a low payoff is realized, and defect otherwise. If all participants are selfish and aware of this, no-one will form a group. We therefore expect groups to be formed only between individuals who face sufficient incentives, intrinsic or extrinsic, not to cheat. This leads to the prediction that there will be less group formation under imperfect enforcement, i.e., under treatments 2 and 3 as compared to treatment 1 . Barr and Genicot (2008) presented evidence in support of this prediction.

In treatment 2 group formation relies primarily, if not exclusively, on intrinsic incentives. Given this, we expect participants under treatment 2 to form groups only with others in whom they trust, possibly owing to mutually held feelings of altruism. Hamilton (1964) hypothesized that individuals, human or otherwise, exhibit more altruism towards close kin and for nonhuman species there is now a considerable body of evidence supporting Hamilton's prediction (Brembs 2001). Individuals may also be more inclined to trust those with whom they share religious beliefs and interact frequently via community-based organizations (Platteau, 1994). Social proximity in the form of kinship, co-religion, and co-memberships in CBOs matter under treatment 1 because they reduce group formation costs. If, in addition, they form a basis for altruism and trust, they should be more strongly associated with group formation under treatment 2 compared to treatment 1 . So, our fourth prediction concerning who shares risk with whom is as follows:

Prediction 4: Social proximity in the form of kinship, co-religion and co-memberships in CBOs is more strongly associated with risk sharing under treatment 2 as compared to treatment 
In treatment 3, additional extrinsic incentives are brought into play. Models of repeated interaction between self-interested agents, e.g., Coate and Ravallion (1993), have shown that agreements can be enforced by the threat of exclusion from future interactions. Although in our experiment the risk pooling game is not repeated, under treatment 3 participants have to defect publicly and this may adversely affect the ongoing relationships they have with other villagers. Put another way, the public nature of the defections effectively transforms the group formation in the game into an element in the series of repeated interactions in which the villagers are naturally engaged (Kocherlakota, 1996). This introduces an additional deterrent against defecting which, all other things being equal, will make group formation more attractive under treatment 3 as compared to treatment 2, especially among pairs of individuals who are engaged in ongoing series of repeated interactions such as co-members in religious congregations and CBOs, and even more especially when those interactions are voluntary and, thus, jeopardizable.

Based on this reasoning alone, we would expect more grouping and risk sharing under treatment 3 as compared to treatment 2 and less grouping and risk sharing under treatment 3 as compared to treatment 1. However, this is not what the data show. Barr and Genicot (2008) find less group formation under treatment 3 than under treatment 2 and offer two possible explanations, both relating to the fear of jeopardizing ongoing valuable relationships. In one explanation, participants fear that they may succumb to the temptation to defect publicly on the spur of the moment owing to inconsistent time preferences and choose not to group in the first place as a way of guarding against this temptation. In the other, participants fear that other group members with whom they have valuable ongoing relationships may succumb to the temptation and choose not to group in the first place as a way of guarding against the costly awkwardness that such a defection would cause. Barr and Genicot (2008) formalize this intuition 
with two theoretical models but offer no tests.

Using our rich and diverse dataset, while we cannot distinguish between Barr and Genicot's two explanations, we can conduct a test of what might be referred to as the encompassing prediction that those engaged in ongoing valuable but jeopardizable or vulnerable voluntary relationships, while facing a greater deterrent against defection under treatment 3 , have more to loose if one or other is tempted to defect nevertheless and may refrain from grouping in order to guard against such losses. To do this we need to make a series of informed assumptions about the value and vulnerability of the various relationships between experimental participants that are captured in our data.

Kinship and co-religion may be valuable but are unlikely to be vulnerable. Ties between in-laws are particularly interesting in the Zimbabwean context because they are associated with many reciprocal obligations and, no matter how displeased one is with one's in-laws (or indeed one's spouse), these reciprocal obligations remain and the repeated interaction continues (Holleman, 1969). ${ }^{10}$ Members of the same church may be friends but even if they are not or cease to be following some disagreement their tie of co-religion is likely to remain in place. Indeed, being of the same religion may provide a basis for reconciliation.

In comparison, co-memberships in CBOs are likely to be both valuable and vulnerable. They are valuable because of the vital role that CBOs play in helping villagers solve problems associated with missing markets and public good provision. And they are vulnerable in the sense that each villager is free to leave a CBO if he or she wishes to do so and the collective membership can expel or fractionalize if sufficient agreement to do so is reached. In Zimbabwe, though rare, expulsions and fractionalizations are not unheard of. Thus, co-memberships in

\footnotetext{
${ }^{10}$ Marriage and divorce are voluntary in some societies including the one under investigation. However, our experimental design restricted participation to a single participant per household, thereby precluding married couples from both participating. So, in our dataset kinship corresponds to genetic relatedness and to being in-laws.
} 
CBOs correspond to the jeopardizable voluntary relationships to which Barr and Genicot allude and the following prediction can be made:

Prediction 5: Co-members in CBOs withdraw from group formation under treatment 3 as compared to treatments 1 and 2.

Finally, returning to the analysis of kinship and co-religion presented above, note that these ties may provide a support for group formation under treatment 3 . To the extent that they are valuable, their value is likely to be eroded by defection and this serves as an enforcement mechanism. However, they are robust and could potentially provide a basis for reconciliation in the event of a defection. Thus, with a degree of circumspection owing to its origins, we propose one further prediction:

Prediction 6: Social proximity in the form of kinship and co-religion is more strongly associated with risk sharing under treatment 3 as compared to treatment 1.

\section{Testing strategy}

We do not have detailed information about the negotiations that took place between the participants during the group formation process and, this being the case, we are restricted to a reduced-form analysis. The other constraint placed upon us by our data relates to sample size; for example, we have too few observations to effectively explore non-linearities in the data.

Bearing these constraints in mind, we adopt the approach to group formation analysis proposed by Fafchamps and Gubert (2007) and Arcand and Fafchamps (2010). ${ }^{11}$ This approach uses network notation to represent groups and relies on the estimation of dyadic regression

\footnotetext{
${ }^{11}$ Readers who would like to see a simple Probit analysis of who groups that takes individual and village-level characteristics as explanatory variables should refer to Barr and Genicot (2008).
} 
models of the general form:

$$
m_{i j}=\lambda\left(\beta x_{i j}\right)
$$

where $m_{i j}=1$ if $i$ is in a risk sharing group with individual $j$, and 0 otherwise; and $\lambda($. denotes the logit function. $E\left[m_{i j}\right]$ increases with factors that make $i$ (or $j$ ) more likely to group. $E\left[m_{i j}\right]$ also increases in factors that make $i$ more likely to group with $j$, such as similarity, social proximity, or prior experience of co-grouping.

The $m_{i j}$ 's are not independent of each other and, this being the case, one may be tempted to base the estimation on a joint maximum likelihood function. However, there are several problems with this approach. First, the estimation would require solving a complicated optimization problem with multiple integrals. This could, in principle, be achieved using the Gibbs algorithm, but at a non-negligible cost in terms of programming. Second and more importantly, writing down the joint likelihood function would force the researcher to specify the functional form of the interactions between observations. Theoretically, this could improve efficiency, but it could also result in inconsistent estimates if the specified form of the interaction were wrong. So, we opt for a simpler and more transparent approach whereby we regress $m_{i j}$ on a vector of $i j$-specific regressors applying a logit and correct for interdependence across observations using the method suggested by Fafchamps and Gubert (2007) for dyadic regressions. Train (2003) recommends a similar logit approach to model multiple choice decisions (in our case, whom $i$ groups with) whenever each choice depends in the same way on choice-specific regressors.

As noted by Fafchamps and Gubert (2007), the estimation of dyadic models requires some care regarding the way regressors are incorporated. In our case, the network matrix $M \equiv\left[m_{i j}\right]$ is symmetrical since $m_{i j}=m_{j i}$ by construction. Hence, to ensure that $E\left[m_{i j}\right]=E\left[m_{j i}\right]$ regressors must enter the model in a symmetric form, i.e., such that $\beta x_{i j}=\beta x_{j i}$. For individual-specific regressors $x_{i}$ and $x_{j}$ one simple way of satisfying this requirement is to enter regressors in the 
form $\left(x_{i}+x_{j}\right)$ and $\left|x_{i}-x_{j}\right|$. As well as being simple, this approach leads to readily interpretable results. The coefficient on $\left|x_{i}-x_{j}\right|$ captures assortative matching: if the coefficient is negative, it indicates that the more individuals differ with respect to variable $x$ the less likely they are to be in the same group. The coefficient of $\left(x_{i}+x_{j}\right)$ captures the direct effect of variable $x$ on $E\left[m_{i j}\right]$, that is, on the likelihood of joining a (larger) group. See Fafchamps and Gubert (2007) for details. ${ }^{12}$

Taking all these factors into account, we estimate a model of the following form:

$$
\begin{array}{r}
m_{i j}=\lambda\left(\beta_{0}+\beta_{1} t_{i j}+\beta_{2} d_{i j}+\beta_{3}\left(t_{i j} \times d_{i j}\right)\right. \\
\left.+\beta_{4}\left|z_{i}-z_{j}\right|+\beta_{5}\left(z_{i}+z_{j}\right)\right)
\end{array}
$$

where: $d_{i j}$ is a vector of the characteristics of the relationship between individuals $i$ and $j$, i.e., kinship and co-membership in religions and CBOs, and $d_{i j}>0$ indicates the presence of a given relationship, $d_{i j}=0$ its absence; $t_{i j}$ is a vector of treatment dummies; $z_{i}$ is a vector of the relevant characteristics of individual $i$ including his or her gender, age, education, income, wealth, and as a proxy for their risk attitudes, their gamble choice $g_{i}^{1}=\{1, \ldots 6\}$ in round 1 ; and the $\beta$ 's are parameters to be estimated.

Before we proceed any further, note that our ability to identify the predicted effects by estimating model (1) depends on the experiment not being embedded within an ongoing, community-wide risk sharing arrangement in every village. If the experiment is perfectly embedded within a community-wide risk sharing equilibrium with perfect truth-telling, grouping to share risk within the experiment is superfluous, i.e., brings no additional risk sharing benefit to participants. Hence, if the cost of forming a group for the experiment were positive, however

\footnotetext{
${ }^{12}$ When, in addition, each node $i$ has the same number of links (which is not the case here), it is not possible to identify factors that make it more likely for $i$ to have more links. This renders the regressors of the form $\left(x_{i}+x_{j}\right)$ redundant.
} 
small, we would observe no group formation and, hence, all the coefficients in (1) would be statistically indistinguishable from zero. Provided this is not the case, we can rule out perfect embeddedness, in which case experimental features do matter and can be used to draw inference about underlying behavioral determinants.

We use model (1) to test the predictions presented in the previous section. Significant elements in $\beta_{1}$, identify the impact of the treatments on the likelihood of an individual joining a group. Since treatment 1 is the omitted category, a negative coefficient on treatment 2 and a larger negative coefficient on treatment 3 would be consistent with the findings of Barr and Genicot (2008).

The sign and significance of coefficients $\beta_{2}, \beta_{3}$, and $\beta_{4}$ provide information regarding the effects of group formation costs and intrinsic and extrinsic motivations on who groups with whom. A significantly positive $\beta_{2}$ supports Prediction 3 as it provides evidence that group formation costs are important and decline with social proximity $d_{i j}$. A significantly negative $\beta_{4}$ corresponding to characteristic $z$ supports Prediction 2 as it provides evidence that $i$ 's and j's who are more similar in terms of $z$ are more likely to join the same group. Further, if the element in $\beta_{4}$ that corresponds to the dyadic difference in risk attitudes, $\left|g_{i}^{1}-g_{j}^{1}\right|$, is significant and negative it supports Prediction 1 as it provides evidence that $i$ 's and $j$ 's who are more similar in terms of their risk attitudes are more likely to group together.

Significant elements in $\beta_{3}$, the coefficients on the interaction terms $t_{i j} \times d_{i j}$, indicate that the importance of different types of social proximity varies across treatments. Since treatment 1 is the omitted category, a significant positive $\beta_{3}$ for treatment $2 \times d_{i j}$ provides evidence in support of Prediction 4, that social proximity facilitates group formation when enforcement depends on intrinsic incentives alone. A significant positive $\beta_{3}$ for treatment $3 \times d_{i j}$ is evidence that the 
social proximity and repeated interactions associated with $d_{i j}$ support social enforcement. ${ }^{13} \mathrm{~A}$ significant negative coefficient on the interaction between treatment 3 and co-memberships in CBOs provides support for Prediction 5. Significant positive coefficients on the interaction between treatment 3 and kinship and treatment 3 and co-religion provide support for Prediction 6. A significant negative $\beta_{3}$ indicates that individuals are choosing to protect the social ties and repeated interactions associated with a specific type of social proximity from the consequences of someone defecting in public during the experiment.

Finally, significant elements in $\beta_{5}$ identify characteristics associated with joining larger groups or with joining a group rather than staying a singleton. ${ }^{14}$ The term $\beta_{5}\left(z_{i}+z_{j}\right)$ are included primarily as controls. However, it is useful to note that a significantly negative coefficient on $g_{i}^{1}+g_{j}^{1}$ provides evidence that less risk averse individuals are less likely to join risk sharing groups.

Winnings $w_{i}$ from round 1 are also included in $z$. If participants see winning as an indication of acumen or luck and if these attributes are universally valued, this could lead to assorting on first round winnings and a negative and significant coefficient on $\left|w_{i}-w_{j}\right|$. If participants who were lucky in the first round think they do not need insurance in the second round and, so, choose not to group, we would observe a negative coefficient on $\left(w_{i}+w_{j}\right) \cdot{ }^{15}$

Model (1) is estimated using a logit. As emphasized earlier, it is essential to correct standard errors for non-independence across observations. Non-independence arises principally because residuals from dyadic observations involving the same individual $i$ or $j$ are correlated, negatively or positively, with each other. Standard errors can be corrected for this type of nonindependence either by clustering by village, as in Arcand and Fafchamps (2010), or by applying

\footnotetext{
${ }^{13}$ Under treatment 3 , reputational considerations in general should raise $\beta_{2}$, the coefficient on the treatment dummy, but should not generate any significant interaction term.

${ }^{14}$ To see why, suppose that individuals with a large value of $z$ form larger groups. This implies that $E\left[m_{i j}\right]$ is an increasing function of $z_{i}+z_{j}$ - and hence that $\beta_{5}$ is positive.

${ }^{15} \mathrm{~A}$ negative coefficient on $\left(w_{i}+w_{j}\right)$ could also potentially result from a wealth or income effect.
} 
the method proposed by Fafchamps and Gubert (2007). Both approaches correct for possible non-independence within dyadic pairs sharing a common $i$ or $j$. Clustering by village also corrects for other forms of non-independence across dyads participating in the same experimental session. However, the estimates of the standard errors that the second approach returns are consistent only when the number of villages is large. ${ }^{16}$ Given that we have data from only 14 villages, we use the method proposed by Fafchamps and Gubert (2007).

As treatments are randomly assigned to villages, it should not be necessary to control for village characteristics. However, because the number of villages is small, unbalancedness across villages is a concern (see Table A1 in the appendix). To correct for this, village fixed effects are included in some specifications.

\section{The data}

The experiments were conducted in 2001 in 23 Zimbabwean villages. However, in this paper we use the data from only 14 . Of the remaining 9 , three were assigned to a control treatment in which no group formation was allowed and 6 were not fully enumerated during the various surveys upon which we draw. The control treatment villages contain no information about group formation and are thus dropped from the analysis presented here. The 6 villages that were not fully enumerated have incomplete information regarding household income, wealth, kinship, religion and memberships in CBOs. When we cross the data to generate dyadic observations, incompleteness leads to a massive loss in usable experimental observations, raising the possibility of selection bias. For this reason we prefer to omit these villages from our analysis. Since villages were randomly assigned to treatments, this should not affect the validity of our inference.

\footnotetext{
${ }^{16}$ Cameron, Gelbach and Miller (2008) provide simulation results showing that when the number of clusters is less than 30, clustering may result in incorrect standard errors.
} 
Of the 14 villages in our sample, 10 were established in the early 1980s as part of a land redistribution programme. These resettled villages are relatively small and geographically concentrated. Owing to the randomness of the settler selection process, inhabitants of these villages are less likely to be genetically related than members of non-resettled villages. However, in the large majority of cases they have lived in the same village for more than a decade, they engage in more associational activity and share more marriage ties (Barr 2004, Dekker 2004).

Data on each participant's characteristics, such as age, gender, years of education and their position within the household, were collected at the time of the experiment. These data are complemented by survey data relating to the participants' households. The household surveys were conducted prior to the experiments, so any variables generated using the survey data cannot be influenced by the outcomes of the experiment.

As measures of household income and wealth, we use the variables constructed by Trudy Owens and Hans Hoogeveen on the basis of the 1999 round of the Zimbabwe Rural Household Dynamics Study (ZRHDS) collected by Bill Kinsey. Wealth is measured in terms of livestock. Kinsey, Burger and Gunning (1998), Gunning, Hoddinott, Kinsey and Owens (2000), and Hoogeveen and Kinsey (2001) discuss this dataset in detail.

The data on memberships in various religious groups and community-based organizations (CBOs) are drawn from a survey by Barr in 2000 that focused on the same households and individuals therein (see Barr (2004) for details). In the case of the latter, we focus on comemberships in CBOs with an explicit economic purpose, e.g., micro-finance, mutual insurance, funeral societies, irrigation and livestock rearing cooperatives as it is these that are both valuable and voluntary.

Our data on family and marriage ties are derived from a specifically designed social mapping exercise conducted in 1999 and 2001 by village focus groups involving at least one representative 
from each household residing in each village (Dekker 2004). In the analysis, genetic relatedness is captured by a dummy variable taking the value 1 for relatives and zero otherwise. Relatedness by marriage is captured by a second dummy variable taking the value 1 for dyads related by marriage but not genetically and zero otherwise.

\section{$6 \quad$ Descriptive statistics}

Table 2 presents the characteristics of the 382 participants who took part in both rounds of the experiment in the 14 villages. ${ }^{17}$ These observations form the basis for our analysis. The sample is evenly split between men and women. The average participant is middle-aged and has slightly more than primary education. Two thirds are married and are either household heads or the spouses of household heads. Both annual household monetary income and livestock wealth are approximately log-normally distributed and are incorporated into the analysis in log form. ${ }^{18}$ The majority of participants belong to a religious community, most often one of the many local apostolic religions existing in Zimbabwe. On average, participants belong to between three and four economic CBOs.

Also reported in Table 2 are the proportions of the sample playing under each of the treatments, the proportion who joined groups, the average gamble choices in each round of the experiment, and the average winnings per participant in each round. Across the sample, just under half of the participants join sharing groups in the second round of the experiment and average group size is 3.17 . Figure 1 presents a histogram of the size of group joined by each

\footnotetext{
${ }^{17}$ Of the participants in the first round in these villages, 19 did not turn up on the second day, sending a replacement from the same household in their stead. Because we do not have first round gamble choice data for the replacements, they are excluded from the analysis that follows. However, if we do not control for gamble choice in the group formation logits and include the replacements, the other findings remain qualitatively unchanged.

${ }^{18}$ To avoid losing observations with no income or livestock wealth, we use $\log ($ crop income +1$)$ and $\log (\operatorname{livestock}$ wealth+1). Livestock wealth is measured in money terms using local market prices and household data on numbers of livestock of different types.
} 
participant under each of the three treatments. Participants who do not join a group appear on the left as 'groups' of size 1. Groups are small even under treatment 1 and are smaller still under treatments 2 and 3. Further, as shown by Barr and Genicot (2008), the propensity to group is lowest under treatment 3 when extrinsic incentives are allowed to come into play.

Several other individual-level descriptive statistics relating to the experiment are worth mentioning even though they are not apposite to our predictions. First, 48 and 46 percent of the participants won the higher payoff from their gambles in rounds 1 and 2 respectively and winning the higher payoff was not correlated across the rounds. These statistics indicate that the gambles were fair and independent. ${ }^{19}$ Second, few participants reneged during the experiment: under treatment 2, 37 participants joined groups, 15 of those went on to win high payoffs and, thus, may have been tempted to defect, but only 3 did so; under treatment 3, 45 participants joined groups, 24 of these went on to win high payoffs, but only one defected. With so few defections, it is impossible to investigate their determinants. However, the descriptives suggest that participants were quite adept at identifying trustworthy partners and tended not to be tempted to defect, especially in public. ${ }^{20}$

Table 3 presents the characteristics of all the possible pairs or dyads of participants that can be made out of the 382 individual participants. By "possible pairs or dyads' we mean dyads that could have chosen to join the same risk sharing group within the experiment. These are all within-village dyads as, by design, between-village dyads could not group together.

Only $7 \%$ of all possible dyads joined the same risk sharing group. Even under treatment 1 where there was perfect exogenous enforcement, only $12 \%$ of the dyads joined the same group. ${ }^{21}$

\footnotetext{
${ }^{19}$ Post-play, group discussions indicated that, while the participants did not have a good grasp of the notion of independence, they did consider the gambles to be unfixable and fair.

${ }^{20}$ Interestingly, the one defector under treatment 3 was a visitor to the village in which she played. She was scheduled to and indeed did get on a bus back to the nearby town only a few hours after the second session was completed.

${ }^{21}$ Treatment 2 is under-represented in the dyadic sample because villages had to be dropped owing to incomplete data.
} 
Straight away this suggests that either the equal sharing rule deterred participants with dissimilar risk preferences from grouping together or group formation costs and enforcement issues affected grouping decisions.

Only $20 \%$ of the dyads belong to the same religious group. This reflects the diversity of faiths present in each of the villages. According to our data the number of religions within each village varies from 4 to 13 with 20 to 30 being represented in the dataset as a whole. ${ }^{22}$ It was because of this diversity that we decided to treat co-religion as a tie in the same way we treat co-memberships in CBOs as ties rather than treating it as a personal characteristic.

The average dyad has approximately one co-membership in an economic CBO, although the maximum number of co-memberships in economic CBOs is 9. Owing to the prevalence of resettled villages in our sample and the fact that each household could send only one participant to the experiments, only 2 percent of the dyads in our sample are genetically related. Relatedness by marriage is more commonplace: 19 percent of the dyads are related by marriage. Dekker (2004) proposes and finds support for the notion that, in the resettled villages, marriage has been used to create social ties between households. ${ }^{23}$

Since the gamble choice variable $g_{i}^{1}$ takes values from 1 to 6 , the maximum difference in gamble choice is 5 and the maximum sum is 12 . The average absolute difference in gamble choices is 1.23 . The average difference in round 1 winnings within dyads is 116 Zimbabwean dollars and the average sum of round 1 winnings is 324 Zimbabwean dollars.

\footnotetext{
${ }^{22}$ We cannot be more accurate about the total number of religions because, in each village, local church or congregation names rather than generic names were sought in the first stage of the data collection in order to maximize the accuracy of the second stage.

${ }^{23}$ We have no information on geographical proximity. However, the study villages are small and geographically concentrated, i.e., not interspersed with fields. The majority of participants have lived in the same village for one or two decades: Gans (1968) and Michaelson (1976) both find that the importance of geographical proximity as a determinant of tie formation declines over time.
} 


\section{$7 \quad$ Econometric analysis}

Coefficient estimates and corresponding standard errors for model (1) are presented in Table

4. All standard errors and corresponding indicators of significance are corrected for dyadic clustering. The logit model in the first column includes two treatment dummies (treatment 1 is the basis for comparison) and the four social tie variables described above but no interaction terms. This model identifies the raw treatment effects $\beta_{1} t_{i j}$. The logit model in the second column also includes the interaction terms $\beta_{3}\left(t_{i j} \times d_{i j}\right)$ and provides the first set of test results relating to our six predictions. The significance of the coefficients on the interaction terms included in the regressions tell us whether the effects on grouping of each social tie in treatments 2 and 3 differ from its effect in treatment 1 . To establish whether each social tie has a significant effect on grouping in either treatment 2 or treatment 3, we have to test whether the sum of the coefficient on the appropriate interaction term and the coefficient on the social tie in treatment 1 is significant. This is what the linear restriction tests reported at the bottom of the table do. In the third column the uninteracted treatment dummies are replaced by a full set of village dummies. This model provides a second set of test results. Once again, linear restriction test results are also reported.

Before turning to the results pertaining to our six predictions, note that one of the treatment dummies is statistically significant in columns 1 and 2 . This rules out perfect embeddedness of the experiment within an ongoing community-wide risk sharing arrangement. ${ }^{24}$ Once again, in accordance with Barr and Genicot (2008), there is significantly less group formation under treatment 3 , when social sanctioning is possible. Treatment 2 is intermediate in terms of its impact on group formation but, in the presence of all the controls, it is statistically indistinguishable

\footnotetext{
${ }^{24}$ Post play interviews with participants in the control villages where group formation was not proposed by the experimenter provide further evidence against perfect embeddedness; in none of the control villages did participants spontaneously agree to share winnings amongst themselves.
} 
from treatment 1 .

\subsection{Results}

Prediction 1: The difference in round 1 gamble choices, $\left|g_{i}^{1}-g_{j}^{1}\right|$, is never significant. So,

Prediction 1 is not supported: group formation in the experiment is not assortative with respect to risk attitudes. ${ }^{25}$ The sum of round 1 gamble choices, $g_{i}^{1}+g_{j}^{1}$, is also never significant. This indicates that risk averse individuals are no more likely to join sharing groups or to form larger groups. ${ }^{26}$ The coefficient on the sum of round 1 winnings, $w_{i}+w_{j}$, is negative and significant in column 1 suggesting that participants who won more in round 1 are less likely to group in round 2. However, this result is not robust to the inclusion of the village fixed effects.

Prediction 2: All three models in Table 4 provide strong evidence of assortative grouping with respect to gender, i.e., the coefficient on the dyadic differences in gender is negative and highly significant. This is consistent with Prediction 2 which states that participants are more likely to group with others who are similar to themselves. This may be because, for them, group formation is less costly. ${ }^{27}$

Prediction 3: The model in column 1 indicates that, on average across all treatments, genetically related dyads are more likely to group. However, the coefficient on this variable uninteracted is insignificant in columns 2 and 3, indicating that genetic relatedness is not significantly associated with grouping under treatment 1, i.e., when only group formation costs are important. The linear restriction tests in columns 2 and 3 indicate that genetic relatedness

\footnotetext{
${ }^{25}$ In a similar experiment, but involving only treatment 2 and conducted in Colombia Attanasio et al (2009) found evidence of assorting on risk attitudes, but only among close family and friends. We cannot seek to replicate their finding owing to the fact that we have no data on ties of friendship. Other factors that may have contributed to Attanasio et al's relative success in identifying this effect are the size of their sample, over 80,000 dyads with almost 4,500 of these being close family or friends, and the greater variation in their participants gamble choices.

${ }^{26}$ There is also no evidence of assortative matching on risk preferences even when the analysis is restricted to the sub-sample assigned to treatment 1, i.e, group formation under external enforcement.

${ }^{27}$ Barr, Dekker and Fafchamps (2009) show that assorting with respect to gender is not owing to trust: there is least gender assorting under treatment 2 when trust matters most.
} 
has a significant effect on group formation under treatment 3, where its cost-lowering capacity is combined with its capacity to support enforcement based on social sanctions, even though neither of these capacities is sufficient to generate a significant effect on its own.

Once the village dummies are introduced, there is evidence that co-memberships in economic CBOs increase the likelihood of grouping together under treatment 1 . This finding is consistent with Prediction 3 and suggests that prior experience of grouping together voluntarily leads to lower group formation costs.

Prediction 4: Only one of the interaction terms involving the treatment 2 dummy is significant and, even then, in only one of the models. Prior to the introduction of village dummies, i.e., in column 2, co-memberships in economic CBOs are associated with an increased likelihood of grouping together under treatment 2 both in absolute terms and as compared to treatment 1. This findings is consistent with Prediction 4. However, this effect is not observed in column 3. The introduction of village dummies alters the apparent nature of the effect of CBO co-memberships on group formation from being trust-based to cost-based. We will return to this issue below.

Prediction 5: The coefficient on the interaction term between the treatment 3 dummy and co-memberships in economic CBOs is negative, significant and robust to the inclusion or exclusion of the village dummy variables. This is consistent with Prediction 5. However, the size of this effect varies between columns 2 and 3. The model in column 2 indicates that the desire to protect these valuable ongoing relationships from the possible effects of a public defection significantly outweighs their effect on the cost of group formation and trust, whereas the model in column 3 indicates that the desire to protect these relationships simply cancels out their effect on the cost of group formation and trust.

Prediction 6: The coefficients on the interaction terms between the treatment 3 dummy 
and co-religion and the treatment 3 dummy and marriage ties are positive, significant and robust to the inclusion or exclusion of the village dummy variables. In addition, as mentioned above, genetic relatedness supports group formation under treatment 3, where its cost-lowering capacity is combined with its capacity to support enforcement based on social sanctions. These findings are consistent with Prediction 6 and indicate that co-religion and kinship, especially marriage ties, support enforcement based on social sanctioning.

\section{Summary and discussion}

The aim of this paper was to investigate the extent to which available enforcement mechanisms affect who shares risk with whom. Our approach was to apply dyadic regression analysis to data from a specifically designed behavioral experiment, two surveys, and a genealogical mapping exercise all undertaken in the same villages. The experimental element in the research design was critical as it excluded any causal influence running from who was sharing risk with whom to the enforcement mechanism adopted. Three treatments were applied during the experiment, each corresponding to a different enforcement mechanism: perfect enforcement by an outside party; enforcement through intrinsic incentives such as altruism and mutual trust; and enforcement through extrinsic incentives arising from the fear of social punishment possibly in the form of exclusion from future interactions.

Combining insights from the rich and diverse theoretical literature on risk sharing with ethnographic information pertaining to the context in which we conducted the experiment we derived six predictions concerning who would share risk with whom during the experiment and how this would vary across the three enforcement mechanisms.

Five out of the six predictions received at least some support from the data: in accordance with Prediction 2, participants of the same gender were more likely to group together to share 
risk; in accordance with Prediction 3, there is weak evidence that genetic relatedness and comemberships in CBOs serving an economic purpose support risk sharing under treatment 1, although in each case the identification of the effect depends critically on the model estimated; in accordance with Prediction 4, co-memberships in CBOs may be of greater support to risk sharing under treatment 2, i.e., when trust is important, although once again this finding is not robust across model specifications; in accordance with Prediction 5, those with co-memberships in CBOs serving an economic purpose withdrew from grouping under treatment 3, i.e., when social punishments could be used to enforce grouping to share risk; and in accordance with Prediction 6, kinship, especially in the form of marriage ties, and co-religion are more strongly associated with risk sharing under Treatment 3 compared to Treatment 1, i.e., when grouping to share risk is enforced by the experimenter.

The analysis depended on the estimation of a reduced form model of group formation. However, the findings are consistent with group formation being easier or less costly between individuals of the same sex and, possibly between kin and those who share more co-memberships in CBOs serving an economic purpose. That, according to our data, similarities in age, withinhousehold status, education, income, wealth, and marital status are not associated with an increased likelihood of grouping is also worthy of note. It suggests that the villages included in our study are very cohesive and inclusive. However, before being presented as a conclusion, this finding needs to be corroborated by further research focusing on the groups and networks that are formed in everyday life, as for instance undertaken by Barr, Dekker and Fafchamps (2010c).

Co-memberships in CBOs serving an economic purpose may also provide a basis for mutual trust. However, here, in particular, the perturbing of the result when village dummies are added to the model needs some consideration. The density of each of the four types of social ties included in our models varies significantly across villages, with the variation being most 
significant in the case of co-memberships in economic CBOs. This is undoubtedly leading to problems of identification and indicates that future studies should involve a larger number of villages, reduce the number of treatments applied, or aim to match the village samples across treatments rather than assigning treatments randomly.

Because there are so few kin relations in the sample, we are perhaps not too surprised that results fail to show ties of kinship to embody trust. However, we remain disappointed with our null finding concerning the role of co-religion in supporting trust. Here, once again, we suspect that low power owing to small sample size is the origin of the problem.

Finally, it is probably appropriate to mention that we regret choosing not to collect data on friendship as this, more than any other form of social tie is likely to embody trust. At the time when we conducted the experiments reported here, we had not discovered how easy it is to collect data on who, within an experimental session, recognizes whom as a friend.

Our findings concerning which type of social ties support informal enforcement based on social sanctioning and which are protected from the consequences of social sanctions having to be applied are considerably more robust. Co-religion provides a foundation for enforcement based on social sanctioning, possibly because of religious traditions about transgressions, admissions, contrition and forgiveness. Marriage ties between in-laws also provide a basis for enforcement through social sanctioning, although, here, contrition and forgiveness would seem less likely to be involved.

Finally, pairs of participants who, through their co-memberships in CBOs serving an economic purpose, are engaged in highly valued but vulnerable repeated exchanges are more likely to group when a third party is enforcing the contract or the contract is supported by trust alone but withdraw from group formation when there is a risk of public defections. Sadly, our data did not allow us to distinguish between the two explanations that Barr and Genicot (2008) proposed 
and so it remains up to other researchers to establish whether it is the fear of oneself or others being tempted to renege publicly on a new informal contract that looms largest in the minds of those who withdraw from setting up such new contracts.

Despite being unable to establish which of these fears looms largest, we view the evidence in support of Barr and Genicot's (2008) theoretical explanations as to why less risk sharing was observed under treatment 3 compared to treatment 2 as our most important contribution. This is because it highlights a weakness in some widely accepted theories of risk sharing and provides support for a previously unacknowledged explanation as to why many apparently beneficial interactions do not take place. It suggests that villagers are very protective of their valued series of repeated interactions and take the potential impact of any prospective interaction on their tried and tested ones into account when such new prospects emerge.

In addition, the fact that it is co-memberships in economic CBOs that are protected in this way provides direct evidence of the value of CBOs that is not subject to concerns about endogeneity. Such evidence is rare and renders the recent reports indicating that Zimbabwean civil society has suffered from the extreme pressure placed upon it since we conducted our experiments all the more lamentable. A follow-up study in six of the villages included in the analysis above shows that 73 percent of the CBOs enumerated in 2000 no longer exist.

\section{References}

Altonji, J. G., Hayashi, F. and Kotlikoff, L. J. (1992). "Is the Extended Family Altruistically Linked? Direct Tests Using Micro Data.”, Americal Economic Review, 82(5):1177-1198.

Arcand, J.-L. and Fafchamps, M. (2010), Matching in Community-Based Organizations. (mimeograph). 
Bardsley, N. (2005). "Experimental Economics and the Artificiality of Alteration.", Journal of Economic Methodology, 12(2):239-51.

Barr, A. (2004). "Forging Effective New Communities: The Evolution of Civil Society in Zimbabwean Resettlement Villages.", World Development, 32(10):1753-66.

Barr, A. and Genicot, G. (2008). "Risk Sharing, Commitment and Information: An Experimental Analysis.", Journal of the European Economic Association, 6(6):1151-84.

Barr, A., Dekker, M. and Fafchamps, M. (2009), Bridging the Gender Divide: An Experimental Analysis of Group Formation in African Villages. (mimeograph).

Barr, A., Dekker, M. and Fafchamps, M. (2010), The Formation of Community Based Organizations in sub-Saharan Africa: An Analysis of a Quasi-Experiment. (mimeograph).

Besley, T. and Coate, S. (1995). "Group Lending, Repayment Incentives, and Social Collateral.", J. Devel. Econ., 46(1):1-18.

Binswanger, H. P. (1980). "Attitudes Towards Risk: Experimental Measurement Evidence in Rural India.", Amer. J. Agric. Econ., 62(3):395-407.

Bloch, F., Genicot, G. and Ray, D. (2004), Social Networks and Informal Insurance. (mimeograph).

Bourdillon, M., Mashita, T. and Glickmann, M. (1977), Traditional Religion and an Independent Church., Christianity South of the Zambezi, Vol. part 2, Bourdillon, M.F.C (eds), Mambo Press, Gweru, pp. 192-210.

Brembs, B. (2001), Hamilton's Theory., Encyclopaedia of Genetics, Academic Press.

Cameron, A. C., Gelbach, J. and Miller, D. (2008). "Bootstrap-Based Improvements for Inference with Clustered Errors.", Review of Economics and Statistics, . 
Coate, S. and Ravallion, M. (1993). "Reciprocity Without Commitment: Characterization and Performance of Informal Insurance Arrangements.", J. Dev. Econ., 40:1-24.

Cox, D. (1987). "Motives for Private Income Transfers.", J. Pol. Econ., 95 (3):508-543.

Cox, D., Eser, Z. and Jimenez, E. (1998). "Motives for Private Transfers Over the Life Cycle: An Analytical Framework and Evidence from Peru.", Journal of Development Economics, $55(1): 57-80$.

Cox, D. and Fafchamps, M. (2007), Extended Family and Kinship Networks., Handbook of Development Economics, Vol. 4, T. Paul Schultz and John Strauss (eds.), Elsevier, Amsterdam. (forthcoming).

Daneel, M. (1977), The Growth and Significance of Shona Independent Churches., Christianity South of the Zambezi, Vol. part 2, Bourdillon, M.F.C (eds), Mambo Press, Gweru, pp. 177192.

De Weerdt, J. and Dercon, S. (2006). "Risk-Sharing Networks and Insurance Against Illness.", Journal of Development Economics, 81(2):337-56.

De Weerdt, J., Dercon, S., Bold, T. and Pankhurst, A. (2006). "Group-Based Funeral Insurance in Ethiopia and Tanzania.", World Development, 34(4):685-703.

De Weerdt, J. and Fafchamps, M. (2007), Social Networks and Insurance against Transitory and Persistent Health Shocks. (mimeograph).

Dekker, M. (2004). "Sustainability and Resourcefulness: Support Networks During Periods of Stress.", World Development, 32(10):1735-1751.

Fafchamps, M. (1999). "Risk Sharing and Quasi-Credit.", Journal of International Trade and Economic Development, 8(3):257-278. 
Fafchamps, M., Goyal, S. and van der Leij, M. (2005), Scientific Networks and Coauthorship. (mimeograph).

Fafchamps, M. and Gubert, F. (2007). "The Formation of Risk Sharing Networks.", Journal of Development Economics, 83(2):326-50.

Fafchamps, M. and Lund, S. (2003). "Risk Sharing Networks in Rural Philippines.", Journal of Development Economics, 71:261-87.

Foster, A. D. and Rosenzweig, M. R. (2001). "Imperfect Commitment, Altruism and the Family: Evidence from Transfer Behavior in Low-Income Rural Areas.", Review of Economics and Statistics, 83(3):389-407.

Gans, H. (1968), People and Plans: Essays on Urban Problems and Solutions, Basic, New York.

Genicot, G. and Ray, D. (2003). "Group Formation in Risk-Sharing Arrangements.", Review of Economic Studies, 70(1):87-113.

Ghatak, M. (1999). "Group Lending, Local Information, and Peer Selection.", Journal of Development Economics, 60(1):27-50.

Ghatak, M. (2000). "Screening by the Company You Keep: Joint Liability Lending and the Peer Selection Effect.", Economic Journal, 110(465):601-31.

Gunning, J., Hoddinott, J., Kinsey, B. and Owens, T. (2000). "Revisiting Forever Gained: Income Dynamics in the Resettlement Areas of Zimbabwe, 1983-1997.”, Journal of Development Studies, 36(6).

Hamilton, W. (1964). "The Genetical Evolution of Social Behavior.", Journal of Theoretical Biology, 7:1-52. 
Hoff, K. (1996), The Emergence of Organization in Informal Insurance. (mimeograph).

Holleman, J. (1969), Shona customary law: with reference to kinship, marriage, the family and the estate, Manchester University Press, Manchester.

Hoogeveen, J. and Kinsey, B. (2001). "Land Reform, Growth and Equity: A Sequel.", Journal of Southern African Studies, 27:127-36.

Jackson, M. O. (2008), Social and Economic Networks, Princeton University Press, Princeton.

Karlan, D. (2007). "Social Connections and Group Banking.", Economic Journal, 117:52-84.

Kimball, M. S. (1988). "Farmers' Cooperatives as Behavior Toward Risk.", Amer. Econ. Rev., $78(1): 224-232$.

Kinsey, B., Burger, K. and Gunning, J. W. (1998). "Coping with Drought in Zimbabwe: Survey Evidence on Responses of Rural Households to Risk.", World Development, 25(1):89-110.

Kocherlakota, N. R. (1996). "Implications of Efficient Risk Sharing Without Commitment.", Rev. Econ. Stud., 63(4):595-609.

Legros, P. and Newman, A. F. (2007). "Beauty Is a Beast, Frog Is a Prince: Assortative Matching with Nontransferabilities.", Econometrica, 75(4):1073-1102.

Levitt, S. and List, J. A. (2007). "What do Laboratory Experiments Measuring Social Preferences Tell us about the Real World.", Journal of Economic Perspectives, 21(2):153-74.

Ligon, E., Thomas, J. P. and Worrall, T. (2001). "Informal Insurance Arrangements in Village Economies.", Review of Economic Studies, 69(1):209-44.

Michaelson, W. (1976), Man and His Urban Environment: A Sociological Approach, AddisonWesley, Reading, MA. 
Morduch, J. (1999). "The Microfinance Promise.", Journal of Economic Literature, 37(4):15691614 .

Nichols, A. and Schaffer, M. (2007), Clustered Standard Errors in Stata, United Kingdom Users' Group Meeting 2007. available at http://repec.org/usug2007/crse.pdf.

Platteau, J.-P. (1994). "Behind the Market Stage Where Real Societies Exist: Part II - The Role of Moral Norms.", J. Development Studies, 30(4):753-815.

Platteau, J.-P. (1995). "An Indian Model of Aristocratic Patronage.", Oxford Econ. Papers, 47(4):636-662.

Platteau, J.-P. (1996), Traditional Sharing Norms as an Obstacle to Economic Growth in Tribal Societies., Technical report, CRED, Facultés Universitaires Note-Dame de la Paix, Namur, Belgium. Cahiers No. 173

Ravallion, M. and Dearden, L. (1988). "Social Security in a Moral Economy: An Empirical Analysis for Java.", Rev. Econ. and Stat., 70:36-44.

Train, K. E. (2003), Discrete Choice Methods with Simulation, Cambridge University Press, Cambridge.

Udry, C. (1994). "Risk and Insurance in a Rural Credit Market: An Empirical Investigation in Northern Nigeria.", Rev. Econ. Stud., 61(3):495-526. 
Figure 1: Sizes of group joined

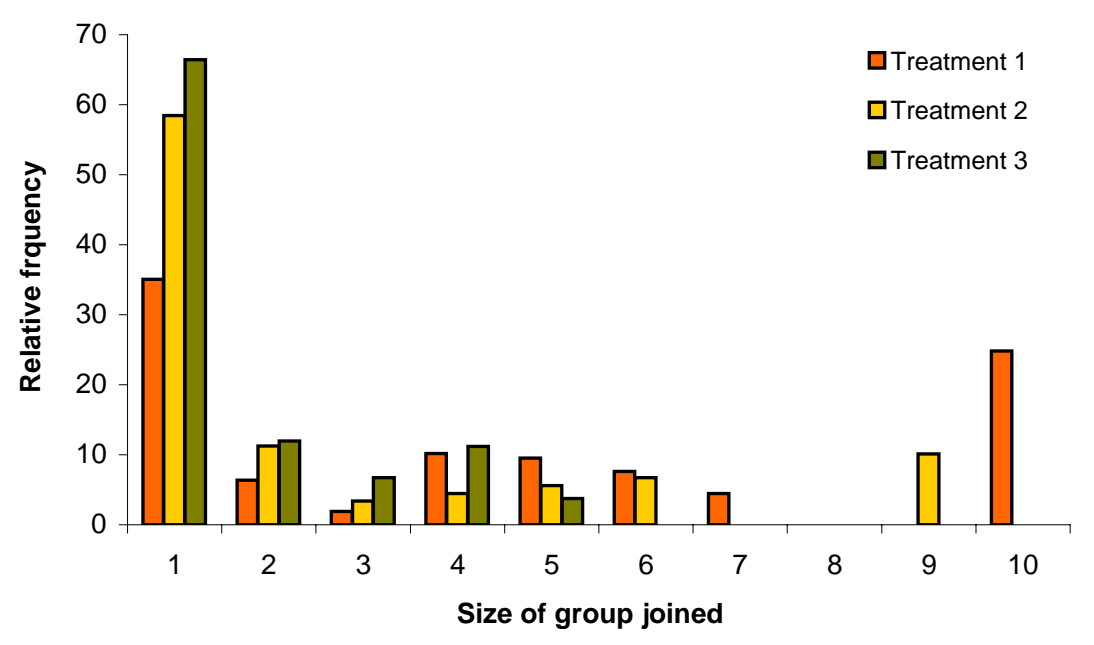


Table 1. Gamble choices in $\mathrm{Z} \$$ and implied relative risk aversion coefficients

\begin{tabular}{cccccccc}
\hline Choice & High payoff & Prob. & Low payoff & Prob. & EV & RA class & RA coeff. \\
\hline $\mathbf{1}$ & 100 & $50 \%$ & 100 & $50 \%$ & 100 & Extreme & infinity to 7.51 \\
$\mathbf{2}$ & 190 & $50 \%$ & 90 & $50 \%$ & 140 & Severe & 7.51 to 1.74 \\
$\mathbf{3}$ & 240 & $50 \%$ & 80 & $50 \%$ & 160 & Intermediate & 1.74 to 0.81 \\
$\mathbf{4}$ & 300 & $50 \%$ & 60 & $50 \%$ & 180 & Moderate & 0.81 to 0.32 \\
$\mathbf{5}$ & 380 & $50 \%$ & 20 & $50 \%$ & 200 & Slight-neutral & 0.32 to 0.00 \\
$\mathbf{6}$ & 400 & $50 \%$ & 0 & $50 \%$ & 200 & Neutral-negative & 0 to -ve infinity \\
\hline
\end{tabular}




\begin{tabular}{lrr}
\hline & Mean & Std. Dev. \\
\hline Subject Characteristics & $52 \%$ & \\
Female & 41.97 & 17.75 \\
Age & 6.76 & 3.21 \\
Years of schooling & $42 \%$ & \\
Household head & $21 \%$ & \\
Spouse of household head & $66 \%$ & \\
Married & 2,562 & 3,374 \\
Annual income (Zim\$) & 11,656 & 10,124 \\
Value of livestock wealth (Zim\$) & $88 \%$ & \\
Belongs to a religious community & 3.30 & 2.85 \\
Memberships in economic groups & 0.77 & 1.45 \\
Genetic relatives in same session & 5.92 & 6.61 \\
Relatives by marriage in same session & $76 \%$ & \\
Resettled household & & \\
& & \\
Experimental variables & $42 \%$ & \\
Played under treatment 1 & $23 \%$ & \\
Played under treatment 2 & $35 \%$ & \\
Played under treatment 3 & $49 \%$ & \\
Joined a group in round 2 & 3.17 & 3.01 \\
Group size (singletons included) & 3.23 & 1.17 \\
Gamble choice in round 1 & 157.13 & 106.60 \\
Winnings in round 1 & 382 & \\
Observations & & \\
\hline
\end{tabular}


Table 3. Characteristics of all possible participant dyads

Mean

Std. Dev.

Co-grouping in the experiment

Chose to join same group in experiment

Chose to join same group under treatment 1

Chose to join same group under treatment 2

Chose to join same group under treatment 3

Prior social proximity:

Belong to same religious group

Co-memberships in economic groups

Related by blood

Related by marriage

\section{Treatments:}

Treatment 1 (perfect, exogenous enforcement)

Treatment 2 (intrinsic enforcement only)

Treatment 3 (intrinsic and endogenous extrinsic)

Gambles:

Difference in Round 1 gamble choice

Sum of Round 1 gamble choices

1.230

6.466

Round 1 winnings:

Difference in Round 1 winnings

116.457

Sum of Round 1 winnings

323.597

10470

$12 \%$

$8 \%$

$2 \%$

$19 \%$

0.940

$2 \%$

$19 \%$

$44 \%$

$16 \%$

$40 \%$

Observations
1.066

1.134

1.621

95.794

150.778 


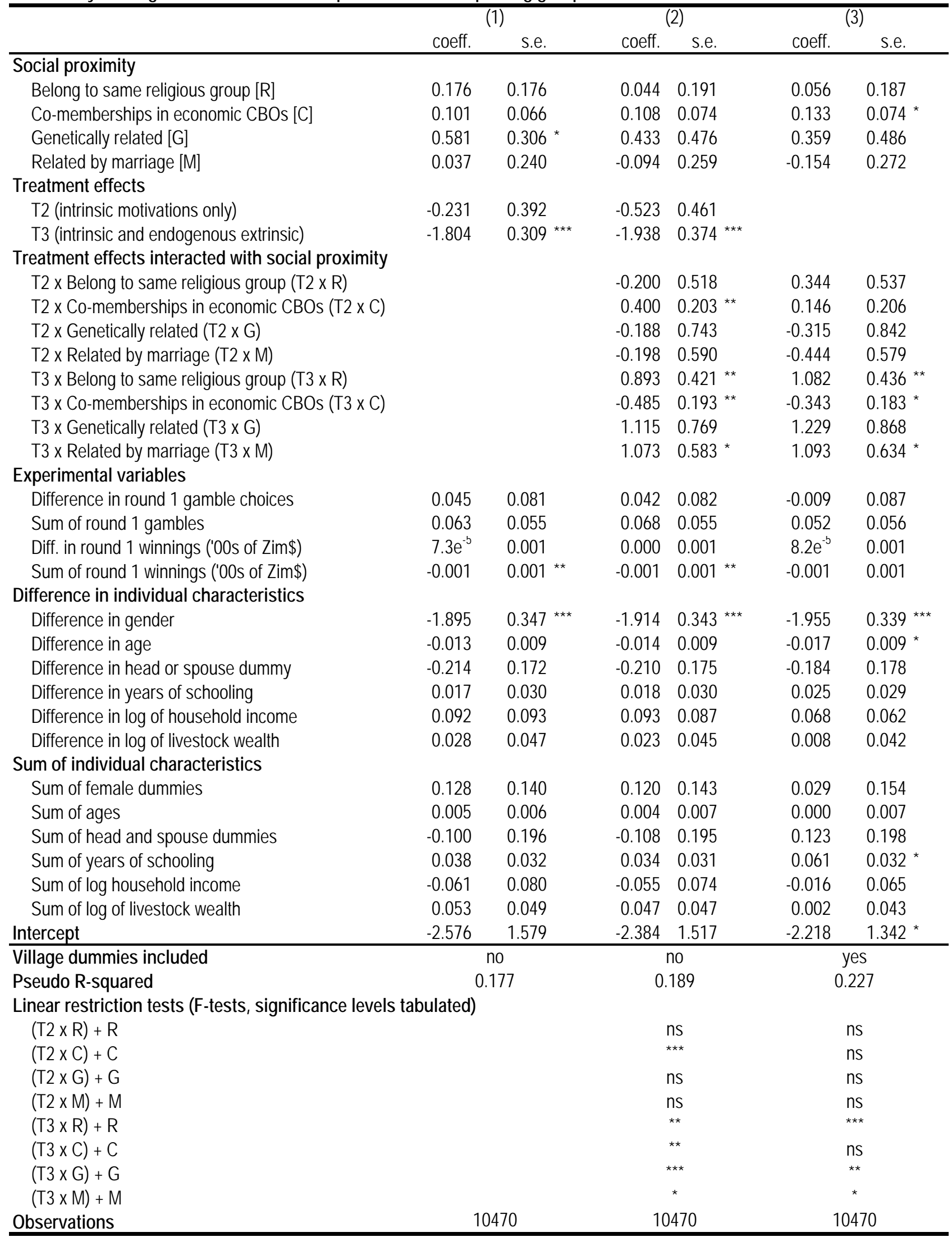

Notes: All standard errors adjusted to account for dyadic non-independence; ${ }^{\star \star \star}$ significant at $1 \%$; ${ }^{\star \star}$ significant at $5 \%$; * significant at $10 \%$. 
Table A1. Characteristics of participants across treatments

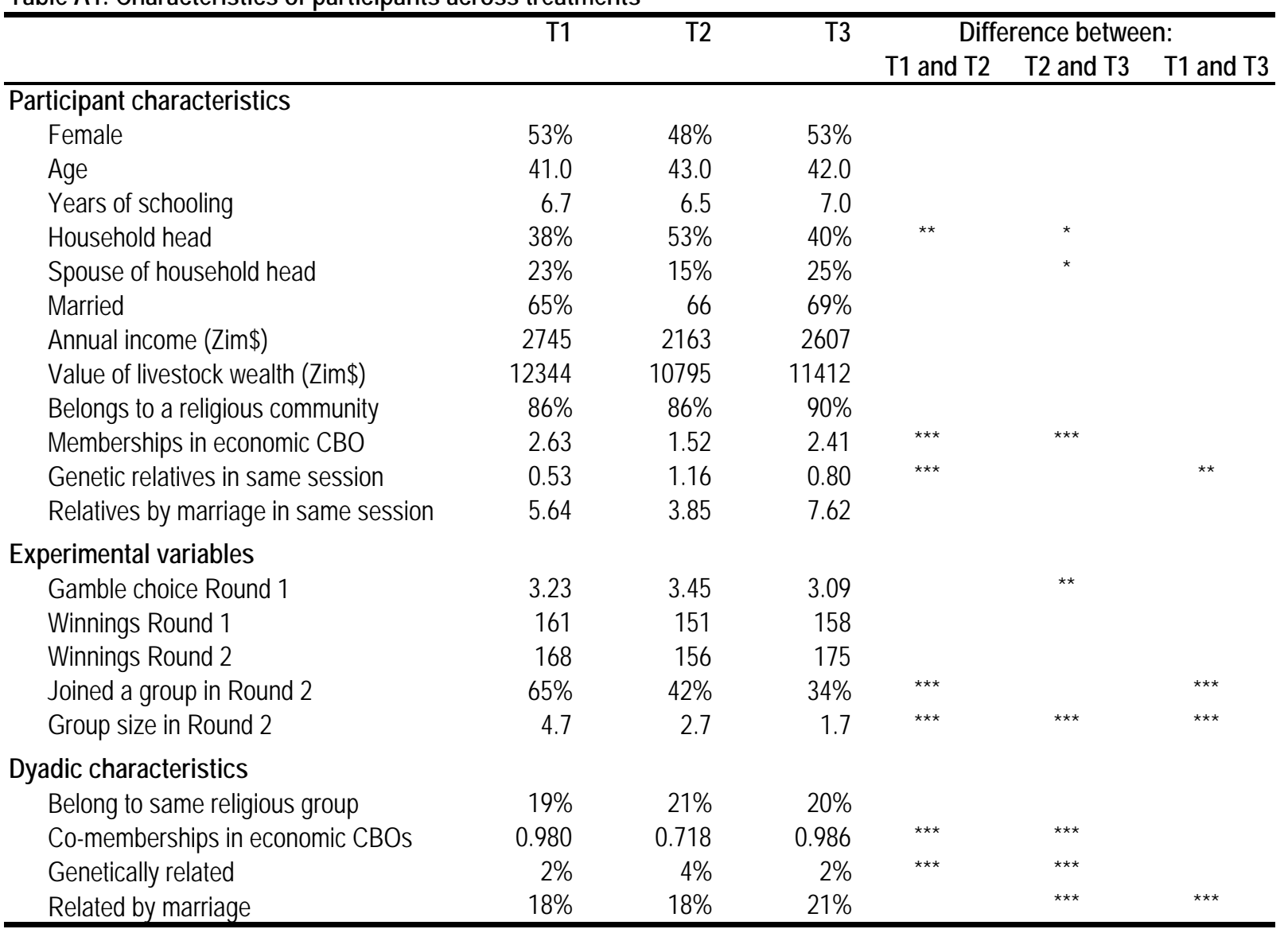

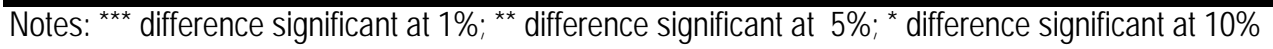

